Artigo Original

\title{
Compreensão e avaliação de um modelo de classificação do esporte na educação física escolar: visão de professores
}

\author{
André Luís Ruggiero Barroso ${ }^{1}$ \\ Suraya Cristina Darido
}

\section{RESUMO}

Introdução: Essa pesquisa tratou do conteúdo esporte, a partir da possibilidade de classificar as modalidades com base na lógica interna. Objetivo: Identificar a compreensão e a avaliação dos professores de Educação Física escolar referente a um sistema de classificação do esporte. Método: Realizou-se uma abordagem de cunho qualitativo, utilizando o método da intervenção pedagógica. Os dados foram obtidos durante a realização de dez encontros, sendo tratados por meio da análise de conteúdo. Resultados: Os resultados apontaram que os participantes demonstraram aprovação pelo modelo adotado, tanto em relação ao professor: estruturação do conteúdo, diversidade de modalidades tratadas, ruptura do tradicionalismo; como para os alunos: despertar do interesse, aumento das possibilidades de aprendizagem, identificação das características comuns e particularidades das modalidades pertencentes à mesma categoria. Conclusão: Considerou-se positiva a avaliação realizada pelos professores em relação ao sistema de classificação, inclusive levando-os a refletir acerca de possíveis reestruturações em suas práticas pedagógicas.

Palavras-chave: Educação Física Escolar. Esporte. Sistema de Classificação.

\footnotetext{
${ }^{1}$ Centro Universitário de Jaguariúna, Educação Física, Jaguariúna -SP, Brasil.

2 Universidade Estadual Paulista, Instituto da Biociências, Departamento de Educação Física, Rio Claro - SP, Brasil.
}

\section{Correspondência:}

André Luís Ruggiero Barroso. Centro Universitário de Jaguariúna (UNIFAJ), Rodovia Governador Dr. Adhemar Perreira de Barros, s/no, km 127, Tanquinho Velho, CEP 13820000, Jaguariúna - SP, Email: al.barroso@uol.com.br 


\section{Comprehension and evaluation of a sport classification model in school physical education: view of teachers}

\section{ABSTRACT}

Introduction: This research related about the sports content, considering the possibility of classifying the modalities based on internal logic. Objective: The aim of this study was to identify the comprehension and evaluation of Physical Education teachers concerning a sport classification system. Method: A qualitative study was conducted, using the pedagogical intervention method. The data were obtained in ten meetings, and submitted to content analysis. Results: The results showed that the participants demonstrated approval towards the adopted model, regarding the teachers: content structure, diversity of included modalities, use of a nontraditional approach; and students: interest, increased learning opportunities, identification of the common characteristics and particularities of the modalities in the same category. Conclusion: The teachers' evaluation of the classification system was considered positive and lead them to reflect about possible changes in their teaching methods.

Keywords: School Physical Education. Sport. Classification System.

\section{Comprensión y evaluación de un modelo de clasificación del deporte en la educación física escolar: visión de profesores}

\section{RESUMEN}

Introducción: Esa pesquisa ha tratado del contenido deporte, a partir de la posibilidad de clasificar las modalidades con base en la lógica interna. Objetivo: El objetivo del estudio fue identificar la comprensión y la evaluación de los profesores de Educación Física escolar referente a un sistema de clasificación del deporte. Método: Se ha realizado un abordaje de carácter cualitativo, utilizando el método de intervención pedagógica. Los datos fueron obtenidos durante la realización de diez encuentros, siendo tratados por medio de análisis de contenido. Resultados: Los resultados señalaron que los participantes demostraron aprobación por el modelo adoptado, tanto en relación al profesor: estructuración del contenido, diversidad de modalidades tratadas, ruptura del tradicionalismo; como para los alumnos: despertar del interés, aumento de las posibilidades de aprendizaje, identificación de las características comunes y particularidades de las modalidades pertenecientes a la misma categoría. Conclusión: Se ha considerado positiva la evaluación realizada por los profesores en relación al sistema de clasificación, incluso llevándolos a reflexionar acerca de posibles reestructuraciones en sus prácticas pedagógicas.

Palabras-clave: Educación Física Escolar. Deporte. Sistema de Clasificación. 


\section{INTRODUÇÃO}

O esporte apresenta-se, conforme apontam autores da pedagogia do esporte, como um fenômeno sociocultural, sendo altamente difundido na maioria dos países, estabelecendo-se como um patrimônio importante da humanidade (BENTO, 2006; GALATTI, 2006; GRECO; BENDA, 2006; PAES, 2001; TUBINO, 2002; SANTANA, 2005).

O desenvolvimento e a disseminação do esporte são contínuos e crescentes, essencialmente devido ao processo de globalização e à atenção pela mídia, tornando-se cada vez mais presente na sociedade. Desta forma, apresenta-se significativa a abordagem do esporte no ambiente escolar, pois se mostra necessário o tratamento de assuntos que fazem parte da vida dos alunos.

Entretanto, nos anos de 1980 o esporte sofre muitas críticas no interior da escola, isso se deu pela forma do direcionamento didático utilizado, objetivandose a deteç̧ão de talentos esportivos, sendo priorizados os alunos que apresentavam maior facilidade na aprendizagem de gestos técnicos específicos de determinadas modalidades esportivas, deixando em segundo plano a maioria dos educandos.

Esse fato gerou, conforme Bracht (2000/1), alguns equívocos a respeito do oferecimento do esporte na Educação Física escolar, porém se revelou a necessidade do estabelecimento de um novo tratamento a este conteúdo durante a prática pedagógica dos professores desse componente curricular.

Algumas questões apresentam-se pertinentes quando se aborda o conteúdo esporte no interior da escola, tais como: O que ensinar sobre esporte? Quais modalidades devem ser abordadas nas aulas de Educação Física? Quais modalidades priorizar em detrimento de outras? Quais critérios utilizar para a seleção das modalidades?

Para responder a essas e a outras questões, inicialmente é determinante considerar a cultura como referência, com o propósito de identificar o que pode ser ensinado nas aulas de Educação Física escolar. Porém, Forquin (1993) adverte que se faz uma escolha do que deve ser tratado na escola, com isso, não é ensinado a cultura na sua íntegra, mas sim, algo da cultura.

Nesse sentido, realiza-se uma seleção dos aspectos culturais mais significativos para serem ensinados do conteúdo esporte, de acordo com os objetivos traçados para a Educação Física escolar, que é "introduzir e integrar os alunos na esfera da Cultura Corporal de Movimento" (BETTI, 1992).

Conforme Tubino (2001) são mais de quinhentas modalidades esportivas, não sendo possível, com o tempo e os espaços escolares, o ensino de todas. Por 
isso é preciso estabelecer algum critério de escolha. Nessa perspectiva, este estudo foi desenvolvido a partir da possibilidade de se estabelecer uma classificação do esporte, apresentando-se como um fator importante para o tratamento apropriado durante os anos de escolarização.

Existem algumas sugestões para classificar as modalidades esportivas, procurando agrupá-las de acordo com as características semelhantes, como esportes individuais, esportes coletivos, esportes com bola, esportes com raquete, esportes aquáticos, entre outras. Formatos desse tipo servem, inclusive, como referência para a determinação das disciplinas do curso de graduação em Educação Física, habilitação em licenciatura e bacharelado, em certas instituições de ensino superior.

De acordo com Parlebás (2001), classificação ocorre a partir do préestabelecimento de critérios, possibilitando a organização de certos elementos em uma determinada quantidade de categorias. Sendo assim, entende-se que a classificação atende ao desejo de organizar um conjunto de objetos ou fenômenos, facilitando a análise dos elementos em questão.

Em relação ao grupo de esportes que apresentam a coletividade, equipe oponente, a utilização de bola e a invasão territorial, como, por exemplo, basquetebol, handebol e futebol, autores da pedagogia do esporte, nos últimos anos, vêm demonstrando atenção acentuada, sendo estruturadas propostas pedagógicas para o trato de modalidades que possuem essas características. É o caso dos estudos de Bayer (1994), Garganta (1998), Paes (2001), Galatti (2006), Greco e Benda (2006), Mesquita e Graça (2006) entre outros.

Parlebas $(1996,2001,2003)$ apresenta a proposta da praxiologia motriz, na qual, ao estruturar uma classificação para os jogos esportivos (incluindo jogos e modalidades esportivas), tem como referência o que denomina de situação motora, entendida como uma série de elementos objetivos e subjetivos que caracterizam uma ação motora de um ou mais indivíduos ao executarem uma tarefa motora, em determinado ambiente.

Assim, Parlebas $(1996,2001,2003)$ considera a situação motora como um sistema de interação global, envolvendo o praticante, o ambiente em que é realizada a atividade e a eventual participação de outras pessoas. Dessa forma, entende que a ação do indivíduo é analisada a partir de um contexto e não a execução do movimento de forma isolada.

Outras propostas para classificação de jogos e de modalidades esportivas podem ser verificadas, como em Freire e Scaglia (2003), que propõem a divisão dos esportes em: individuais, com raquetes, sobre rodas e com bolas; enquanto que Bunker e Thorpe (1982), ao concentrarem-se nos jogos, chegam ao seguinte modelo: jogos de alvo, jogos de parede, jogos de rebater e jogos de invasão. 
Já González (2004, 2006) elaborou um sistema de classificação das modalidades esportivas tendo como referência a lógica interna, definida como "as características de desempenho exigidas pelas situações motoras criadas pelos diferentes tipos de esportes" (GONZÁLEZ, 2006, p. 90).

Em outras palavras, o modelo de classificação de esporte sugerido por González $(2004,2006)$ propicia a distribuição das modalidades esportivas em grupos, denominadas pelo autor de categorias, sendo estas determinadas por critérios que privilegiam as ações motoras intrínsecas às diversas práticas corporais esportivas, reunindo, dessa forma, esportes que apresentam características semelhantes no desenvolvimento de suas práticas. Desta forma, entende-se que a lógica interna refere-se à compreensão dos objetivos da modalidade esportiva, das características táticas e do desempenho dos participantes.

Salienta-se que, para desenvolvimento desse estudo, adotou-se esse sistema de classificação, no qual, para categorizar as modalidades esportivas, de acordo com a lógica interna, González $(2004,2006)$ estipula um sistema de classificação tendo como referência os critérios de cooperação, interação com o adversário, ambiente, desempenho motor e objetivos táticos da ação.

Inicialmente, González $(2004,2006)$ concentra-se nas questões da relação de cooperação e de oposição, gerando, assim, quatro categorias. Primeiro verificase se há ou não uma relação com companheiros em uma mesma equipe, ou seja, se a participação ocorre individualmente ou em grupo, sendo este último caracterizado por dois ou mais integrantes.

No segundo momento, é analisado se ocorre ou não interação direta com o oponente. É importante frisar que essa interação não se relaciona ao estabelecimento do contato físico entre os participantes de equipes distintas, mas sim ao fato de uma ação motora influenciar na decisão das ações dos participantes de outra equipe, como é o caso do voleibol.

Assim, conforme González (2004, 2006), são estipuladas as seguintes categorias: esportes individuais em que não há interação com o oponente, esportes coletivos em que não há interação com o oponente, esportes individuais em que há interação com o oponente e esportes coletivos em que há interação com o oponente.

Ainda de acordo com González (2004, 2006), devido às variações no interior de uma mesma modalidade esportiva, esta pode estar vinculada a duas categorias, por exemplo: no tênis de campo, quando o formato é de apenas um jogador, encaixa-se na categoria esportes individuais em que há interação com o oponente; já no formato de duplas, insere-se na categoria de esportes coletivos em que há interação com o oponente. 
Outro exemplo é a ginástica rítmica, pois na apresentação de apenas uma participante enquadra-se na categoria esportes individuais em que não há interação com o oponente; contudo, na apresentação por equipe, a categoria contemplada é a de esportes coletivos em que não há interação com o oponente.

Dando continuidade aos critérios para classificação do esporte, González (2004, 2006) aponta a questão do ambiente físico no qual é praticada a modalidade, podendo esse ambiente interferir ou não nas ações motoras dos integrantes.

Dessa forma, González $(2004,2006)$ apresenta as modalidades nas quais o ambiente não oferece incertezas para o praticante, denominando essa categoria de esportes com estabilidade ambiental ou praticados em espaços padronizados, como é o caso do basquetebol, da ginástica artística e do judô; e aquelas cujos espaços necessitam de adaptações do praticante, de acordo com as exigências ambientais, que pertencem à categoria de esportes sem estabilidade ambiental ou praticados em espaços não padronizados, como a canoagem, o surfe e a corrida de orientação.

Em seguida, González (2004, 2006), a partir das categorias oriundas de esportes sem e com interação com o adversário, utiliza outros critérios para a formação de subcategorias. No caso dos esportes sem interação com o oponente, o critério baseia-se no tipo de desempenho motor utilizado para a definição do vencedor/perdedor nas diversas modalidades; e nos esportes com interação com o oponente, o critério refere-se ao objetivo tático da ação, ou seja, à exigência imposta aos integrantes para que se atinja o propósito durante o desenvolvimento da prática esportiva.

Os esportes sem interação com o oponente, tendo como critério a comparação de desempenho, divide-se nas seguintes subcategorias:

- Esportes de "marca": são aqueles nos quais o resultado da ação motora comparado é um registro quantitativo de tempo, distância ou peso.

- Esportes "estéticos": são aqueles nos quais o resultado da ação motora comparado é a qualidade do movimento segundo padrões técnico-combinatórios.

- Esportes de precisão: são aqueles nos quais o resultado da ação motora comparado é a eficiência e a eficácia de aproximar um objeto ou atingir um alvo (GONZÁLEZ, 2004, p. 2).

Em relação aos esportes com interação com o oponente, utilizando o critério referente aos princípios táticos do jogo, definem-se as subcategorias:

- Esportes de combate ou luta: são aqueles caracterizados como disputas em que o(s) oponente(s) deve(m) ser subjugado(s), com técnicas, táticas e estratégias de desequilíbrio, contusão, imobilização ou exclusão de um determinado espaço na 
combinação de ações de ataque e defesa.

- Esportes de campo e taco: compreendem aqueles que têm como objetivo colocar a bola longe dos jogadores do campo a fim de percorrer espaços determinados para conseguir mais corridas que os adversários.

- Esportes de rede/quadra dividida ou muro: são os que têm como objetivo colocar/arremessar/lançar um móvel em setores onde o(s) adversário(s) seja(m) incapaz(es) de alcançá-lo ou forçá$\mathrm{lo}(\mathrm{s})$ para que cometa $(\mathrm{m})$ um erro, servindo somente o tempo que o objeto está em movimento.

- Esportes de invasão ou territoriais: constituem aqueles que têm como objetivo invadir o setor defendido pelo adversário procurando atingir a meta contrária para pontuar, protegendo simultaneamente a sua própria meta (GONZÁLEZ, 2004, p. 2).

Após os procedimentos citados, González $(2004,2006)$ finaliza o sistema de classificação do esporte, tendo, portanto, como referência os critérios: da relação com o adversário, a lógica de comparação de desempenho, as possibilidades de cooperação e as características do ambiente físico onde se realiza a prática esportiva.

Pode-se discutir a questão de uma modalidade integrar determinada subcategoria, contudo utilizando características de outra subcategoria. Por exemplo, para a execução do lance livre no basquetebol, o tiro de sete metros no handebol ou o saque no voleibol há necessidade de uma precisão no movimento, todavia, nenhuma dessas modalidades pertence à subcategoria de esportes de precisão.

Ou seja, nesse sistema de classificação não se delimita a modalidade em determinada categoria a partir de momentos isolados do desenvolvimento da mesma, como nos exemplos acima citados, mas sim priorizando os fatores preponderantes de cada uma delas.

Com a estruturação dessas categorias, almeja-se oferecer ao aluno um olhar abrangente do fenômeno esportivo, sendo possível contemplar uma diversidade de modalidades esportivas.

Assim, o objetivo desse estudo foi identificar a compreensão e a avaliação dos professores de Educação Física escolar referente ao sistema de classificação do esporte. Ou seja, verificar com os professores a facilidade de entendimento, de satisfação e as possibilidades pedagógicas da utilização desse sistema nas aulas do componente curricular Educação Física.

Ressalta-se que esse sistema de classificação recebe conotação, pelo fato de ter sido adotado na Base Nacional Comum Curricular para estruturação do conteúdo esporte, pertencente ao componente Educação Física durante o Ensino Fundamental - anos iniciais e finais (BRASIL, 2018). Esse documento apresenta o propósito de determinar os conhecimentos essenciais que o estudante deva ter 
acesso e se apropriar durante a escolaridade nas diversas disciplinas curriculares.

Além disso, esse modelo também serve como referência para o tratamento do esporte no Referencial Curricular do Estado do Rio Grande do Sul, havendo um material didático impresso - caderno do professor e caderno do aluno para o ensino da classificação das modalidades esportivas (RIO GRANDE DO SUL, 2009)3; como também podem ser verificadas demais propostas pedagógicas a partir desse modelo de classificação do esporte (GONZÁLEZ; BRACHT, 2012; GONZÁLEZ; DARIDO; OLIVEIRA, 2017; OLIVEIRA; DARIDO; GONZÁLEZ, 2014).

\section{MÉTODO}

Para desenvolvimento do estudo foi adotada uma abordagem de cunho qualitativo, utilizando-se o método da intervenção pedagógica. De acordo com Damiani et al. (2013), a utilização desse tipo de pesquisa é alicerçada por pesquisadores vinculados à teoria histórico-cultural. Conforme Gil (2010), a intervenção pedagógica opõe-se às pesquisas básicas, nas quais não há intenção de se atingir benefícios diretos; pois, a partir da intervenção, procura-se contribuir com a solução de problemas inerentes à prática.

Para Damiani et al. (2013, p. 58) pesquisas do tipo intervenção pedagógica "são investigações que envolvem o planejamento e a implementação de interferências (mudanças, inovações) - destinadas a produzir avanços, melhorias, nos processos de aprendizagem dos sujeitos que delas participam - e a posterior avaliação dos efeitos dessas interferências".

Nessa perspectiva, o estudo teve o propósito de possibilitar a participação efetiva dos sujeitos envolvidos no desenvolvimento do trabalho. O grupo de participantes foi formado por professores licenciados em Educação Física e atuantes na escola, especificamente nos anos finais do Ensino Fundamental.

A escolha dos professores para participar do estudo atendeu aos seguintes critérios: estar ministrando aulas para os anos finais do Ensino Fundamental, especificamente para oitavo e/ou nono ano; possuir comprometimento com a área da Educação Física escolar, ou seja, apresentar um trabalho que procurasse oferecer um tratamento pedagógico aos conteúdos pertencentes ao componente curricular; disponibilidade para participar da pesquisa; estar presente nos encontros com o pesquisador; poder desenvolver as aulas com os seus respectivos alunos; ser de localidade próxima à do pesquisador, na região do município de Campinas.

\footnotetext{
3 Atenta-se ao fato de que, no Referencial Curricular do Estado do Rio Grande do Sul, o critério das características do ambiente físico não foi considerado para classificação das modalidades esportivas.
} 
Assim, a pesquisa contou com a participação inicial de 8 professores, 4 do sexo masculino e 4 do sexo feminino.

A idade dos participantes apresentou uma variação de 16 anos, sendo que os dois professores mais novos tinham 26 anos e o professor mais velho, 42 anos.

Em relação ao tempo de formação inicial, o menor foi de 4 anos, relativo a dois professores, enquanto o maior tempo registrado foi de 9 anos, referente a três professores.

No quesito tempo de atuação na escola, houve uma pequena variação, verificando-se no mínimo 3 anos e no máximo 7 anos.

Em relação à formação continuada, somente um professor possui especialização voltada diretamente para a Educação Física escolar, enquanto que outros três também possuem curso de especialização, porém não é específico para a área escolar.

No início do primeiro encontro os professores foram informados dos objetivos do estudo e de possíveis publicações em periódicos da área, posteriormente preencheram e assinaram o Termo de Consentimento Livre e Esclarecido. Para manter o sigilo dos participantes, os mesmos foram numerados de 1 a 8 .

Apesar de contar no primeiro momento com a participação de oito professores, a pesquisa desenvolveu-se efetivamente com sete integrantes, pois a professora 3 desvinculou-se do estudo já nos encontros iniciais, por não conseguir desenvolver as aulas na sua unidade escolar, devido ao fato de ter que cumprir o planejamento das aulas e dos eventos da instituição.

No período da pesquisa, que teve a duração de oito meses, os professores atuavam com turmas de oitavo e/ou nono anos do Ensino Fundamental em escolas localizadas nas cidades de Campinas, Jaguariúna e Mogi Guaçu, interior do Estado de São Paulo. Entre as unidades de ensino dos sete professores que participaram integralmente do estudo, cinco eram instituições municipais e duas privadas.

Durante o desenvolvimento da pesquisa foi apresentado o sistema de classificação do esporte aos professores, posteriormente os mesmos desenvolveram as aulas com seus respectivos alunos a respeito do tema e, posteriormente, realizou-se uma avaliação do modelo de classificação. Sendo assim, foram realizados dez encontros, com destaque aos seguintes pontos:

a. Apresentação do modelo de classificação adotado no estudo, para tanto, foi solicitada a leitura do artigo "Sistema de classificação do esporte com base nos critérios: cooperação, interação com o adversário, ambiente, desempenho comparado e objetivos táticos da ação" e a leitura do 
material didático - caderno do professor e caderno do aluno - para oitavo e nono anos do Ensino Fundamental pertencente ao Referencial Curricular do Estado do Rio Grande do Sul; em seguida a realização de discussões acerca do tema e um exercício para os participantes classificarem as modalidades esportivas pertencentes aos Jogos Olímpicos de Verão, conforme os critérios estabelecidos no sistema de classificação;

b. Exposição dos professores de como se deu o desenvolvimento das aulas para tratamento do tema com seus respectivos alunos, acompanhado por apontamentos efetuados pelo pesquisador e pelos demais professores envolvidos no estudo;

c. Avaliação dos professores referente ao sistema de classificação do esporte adotado no trabalho, após o término das aulas envolvendo o tema, sendo destacadas as possibilidades e as dificuldades de utilização do modelo, respeitando-se as realidades educacionais de cada um dos professores participantes da pesquisa.

Desta forma, possibilitou-se nos três encontros iniciais que os professores adquirissem o entendimento do modelo do sistema adotado; posteriormente, ocorreu o desenvolvimento de encontros entre o pesquisador e os professores participantes durante a implementação das aulas dos mesmos com os seus respectivos alunos, havendo quatro encontros nesse período; finalizando, ocorreu a avaliação do modelo, sendo realizados três encontros para discussão acerca das possibilidades e dificuldades de desenvolvimento da proposta de trabalho.

Para tratamento dos resultados obtidos nos encontros entre o pesquisador e os professores participantes da pesquisa foi utilizada a análise de conteúdo. De acordo com Bardin (1991), a análise de conteúdo trata-se de uma técnica de pesquisa, sendo propícia a sua utilização em variados discursos e que possibilita a compreensão de estruturas e de modelos intrínsecos em trechos de textos.

Conforme Bardin (1991) a análise de conteúdo estrutura-se a partir de três etapas: a primeira trata-se de uma pré-análise, relacionando-se aos procedimentos utilizados para obtenção dos dados; a segunda refere-se à exploração do material e ao tratamento dos dados, apresentando o propósito de codificar, classificar e categorizar os dados obtidos; a terceira destina-se à interpretação dos resultados, caracterizando-se pelo aprofundamento da análise dos resultados a partir da estruturação realizada anteriormente.

Ressalta-se que a pesquisa foi aprovada pelo Comitê de Ética em Pesquisa Envolvendo Seres Humanos, tendo registro CAAE: 27550314.3.0000.5465.

Em seguida são apresentadas as discussões dos resultados obtidos por meio 
dos encontros entre o pesquisador e os participantes durante o desenvolvimento da pesquisa.

\section{Resultados E Discussão}

\section{COMPREENSÃo e AVALIAÇÃo do SISTEMA DE CLASSIFICAÇÃo do ESPORTE}

A partir dos relatos de todos os professores verificou-se o predomínio do conteúdo esporte em relação aos demais elementos da Cultura Corporal de Movimento em seus respectivos planejamentos anuais do componente curricular Educação Física, sendo a ginástica o segundo conteúdo mencionado, porém citado apenas por três participantes. O fato de o esporte ser o conteúdo mais comum durante as aulas de Educação Física escolar é algo salientado por diversos autores da área, entre eles Bracht (2000/1), Darido e Rangel (2005), González (2006).

Ressalta-se a importância do conteúdo esporte nas aulas de Educação Física escolar, entretanto se mostra preocupante o pouco ou nenhum tempo destinado a outros elementos, com isso, não apresentando aos alunos a diversidade presente na esfera da Cultura Corporal de Movimento.

Conforme defendido por alguns autores desde a década de 1980, entre eles Betti (1995), Soares et al. (1992), Freire (1992), Bracht (1999), Daólio (2004), a concepção renovadora da Educação Física escolar apresenta, além do esporte, outros conteúdos, como o jogo, a ginástica, a luta e a dança que devem ser tratados nas aulas deste componente curricular. Dessa forma, propõe-se uma melhor formação dos alunos no que se refere ao processo de criação, reprodução e transformação dos elementos culturais pertencentes à área da Educação Física.

Recentemente estudos propõem outros conteúdos para serem incorporados ao ambiente escolar, tais como atividades circenses (DUPRAT e BORTOLETO, 2007), atividades físicas de aventura (FRANCO, 2008), atividades aquáticas, exercícios físicos e práticas corporais alternativas (DARIDO, 2011).

Em relação às modalidades esportivas tratadas pelos professores constatouse uma maior evidência para as quatro modalidades tradicionais - basquetebol, handebol, voleibol e futebol.

Entre os professores que tratam de algumas modalidades que fogem ao rol das quatro convencionais, identificou-se certa diferenciação na escolha das mesmas. Os professores 1, 5 e 6, que atuam na mesma rede de ensino público, apontaram para o tratamento do atletismo e do que denominaram de esportes alternativos, tais como badminton (professores 1 e 5), beisebol (professora 1) e tênis de campo (professores 5 e 6). 
Quanto aos professores que atuam em escolas privadas, no caso da professora 4 ocorre a utilização do meio líquido, devido à infraestrutura da escola, sendo tratados a natação, o biribol e o polo aquático; já na escola do professor 7 destaca-se o desenvolvimento do dodgeball.

O professor 8 foi o que mencionou a maior quantidade de esportes tratados em seu cotidiano, citando, por exemplo, o rúgbi, o beisebol e o tênis de campo.

A pouca diversidade de modalidades esportivas tratadas nas aulas pela maioria dos professores reafirmou a tradição da área em abordar com maior evidência as quatro modalidades tradicionais no trato do conteúdo esporte no ambiente escolar, apresentando-se como uma característica na prática pedagógica de vários profissionais da área, sendo esporadicamente selecionados outros esportes. Essa característica também é presente em outros estudos, tais como Barroso (2008) e Rodrigues (2009).

Entende-se que, o fato de limitar o trabalho pedagógico a um número reduzido de modalidades esportivas restringe as possibilidades de conhecimento dos alunos referente a um elemento da Cultura Corporal de Movimento tão determinante na história da humanidade.

Assim, mostra-se fundamental abrir o leque de possibilidades referente ao esporte como conteúdo da Educação Física escolar, para que o aluno entre em contato com assuntos que ele tem acesso fora desse ambiente; entretanto, conforme alerta Bracht (2000/1), tendo a preocupação de não reproduzir no interior da instituição escolar o que ocorre externamente no esporte com fins direcionados à performance, mas procurando oferecer um tratamento pedagógico apropriado nesse espaço educacional.

Em relação à compreensão do sistema de classificação, o professor 2 era o único que apresentava um conhecimento prévio, pois participou de um curso a respeito desse tema, demonstrando domínio do tema. Em relação aos demais participantes, que tiveram o primeiro contato com o modelo durante 0 desenvolvimento desse estudo, observaram-se algumas interpretações equivocadas ao classificarem determinadas modalidades esportivas.

Exemplo disso foi quando a professora 6 demonstrou certa confusão ao interpretar que a modalidade dos saltos ornamentais poderia se encaixar na categoria esportes de marca. Outra situação foi referente às provas de meio fundo e fundo do atletismo, apontamento realizado pelos professores 6 e 8, pois entenderam que pode ocorrer certa interferência entre os corredores para ocupar um espaço mais adequado na pista ou na rua.

Nessa mesma perspectiva, houve o comentário da professora 4, referindose à maratona aquática, na qual há a busca de um melhor posicionamento durante 
o desenvolvimento da prova, realizada em "águas abertas".

Para explicação, foi ressaltado que a análise da lógica interna tem que ser feita observando a essência da modalidade esportiva, pois podem ocorrer certos apontamentos errados, como, por exemplo, no caso do basquetebol, o jogador ter que apresentar determinada precisão para acertar os arremessos ao longo do jogo, sendo bem característico o lance livre, e, nem por isso, a modalidade se encaixa na categoria de esportes de precisão.

Outras modalidades foram citadas e debatidas entre os participantes, como o caso do hóquei na grama, que utiliza o taco e é praticado em um campo, pois pode haver um conceito enviesado em relação à categoria de esporte de campo e taco. Para esclarecimento, o pesquisador explicou que, caso isso ocorresse, o critério seria o material e o espaço físico utilizado para a prática e não a lógica interna envolvida na modalidade, como é o caso desse modelo de classificação.

A modalidade esportiva do pentatlo moderno também gerou uma discussão interessante, pelo fato de apresentar provas com características que se encaixam em mais de uma categoria.

Um questionamento que chamou muito a atenção e levou ao debate foi em relação a bocha, bilhar e curling, podendo fazer parte do grupo de esportes com interação entre os oponentes, pois, conforme salientado pelos professores, em muitas ocasiões, o jogador irá estruturar a sua ação de acordo com o que o jogador da outra equipe executou anteriormente.

Para esclarecimento dessa questão foi explicado aos professores que, no caso das modalidades citadas, as tomadas de decisão não ocorrem simultaneamente e também não acontecem durante o desenvolvimento ativo das atividades, pois esses esportes se caracterizam por pausas entre as ações para que o jogador defina qual será o procedimento motor adotado. De acordo com González e Bracht (2012) esses fatores são determinantes para classificar qualquer modalidade no grupo de esportes em que há interação entre os oponentes.

Quando os participantes foram solicitados a apontar aspectos negativos do sistema de classificação, apenas dois participantes levantaram possíveis dificuldades: "O que eu vejo é uma confusão, no ciclismo, na natação, eu posso ter interação, tô lá nadando, ele pode me atrapalhar. Eu acho que nas provas abertas, em um espaço aberto, vai ser meio complicado pra eles estarem entendendo" (PROFESSORA 6).

Nesse comentário foi reforçada a preocupação apresentada anteriormente acerca da interpretação sobre a interação entre os competidores, pois, conforme a professora 6 , o aluno pode entender que, em provas como a maratona aquática, 
o ciclismo em pista ou na rua e as provas de corridas do atletismo sem balizamento há uma interferência entre os oponentes.

Foi explicado à professora que realmente pode ocorrer uma interferência, inclusive causando possíveis alterações táticas dos competidores nessas provas, todavia não se estabelece uma relação direta com a tomada de decisão para a execução dos gestos motores, fato que é determinante nos esportes em que há interação entre os adversários, como nas categorias de esportes de invasão, combate, rede/quadra dividida ou muro e campo e taco. Também foi esclarecido à professora 6 que o fato de ela ter apresentado esta interpretação não significa dizer que os alunos também apresentarão, portanto se mostra importante verificar como será o posicionamento dos mesmos, não antecipando algum tipo de problema.

O outro posicionamento desfavorável foi: "Acho que, não sei, de repente perde um pouquinho da especificidade, mas eu acho que é um preço a pagar, você perde um pouco da especificidade, mas ganha em abrangência do tema com os alunos" (PROFESSOR 8).

Nesse comentário, o professor 8 salientou que não foi trabalhada a característica específica de cada uma das modalidades esportivas. Entretanto, foi explicado pelo pesquisador que, nesse instante se tratava de uma unidade didática com o objetivo de ensino do sistema de classificação, contudo isso não inviabiliza a estruturação de outras unidades didáticas para contemplar demais questões e/ou especificidade de determinadas modalidades esportivas.

Quanto aos fatores positivos acerca do modelo de classificação, o professor 8 destacou a quebra do tradicionalismo presente em muitas escolas, quando se limita apenas ao tratamento das quatro modalidades tradicionais, instigando o professor a abordar possibilidades variadas a partir da exploração de esportes menos tradicionais.

Pensando o tradicionalismo da escola, ele quebra completamente. A escola tá baseada tradicionalmente nas quatro modalidades coletivas, o tradicional, isso é uma discussão que data desde a década de 80 e ainda hoje tem reprodução disso em muitos lugares. Se eu tiro o específico da modalidade na escola e trago categoria que abranjam temas maiores, eu aumento a diversidade de conteúdos, eu acho isso muito bom (PROFESSOR 8).

No relato da professora 1 observou-se uma crítica em relação ao seu próprio trabalho, pois se concentra no tratamento dos quatro esportes coletivos, mesmo sabendo que, no caso dessa professora, há uma dependência do planejamento da rede municipal de ensino em que atua.

Seria bem mais interessante, porém muito mais trabalhoso também, trabalhar dessa forma os esportes, do que eu trabalhar, 
como eu trabalho aqui com o programa que tem voleibol, handebol, basquetebol, futsal. Se eu trabalhasse dessa forma, pela classificação, por exemplo, agora nós vamos trabalhar esporte de marca, eu teria uma variedade muito maior de modalidades pra eu trabalhar com meu aluno, ele ia ter contato com um maior número de esportes que eu conseguisse passar, porém ia ser muito mais trabalhoso também montar aula. (PROFESSORA 1).

No enfoque apresentado pelos professores ressalta-se ainda que, ao abordar somente as modalidades tradicionais, na perspectiva do sistema de classificação do esporte adotado no estudo, são contempladas apenas duas categorias: invasão no caso do basquetebol, handebol e futebol e rede/quadra dividida para o voleibol; ou seja, um universo muito restrito, quando se considera a amplitude de possibilidades inerentes ao esporte.

Cabe alertar que, o próprio autor do sistema de classificação de esporte admite o fato de esse modelo não ser completo, ao citar como exemplo o "kabaddi", esporte típico da Índia que se caracteriza como uma modalidade de combate e pela coletividade, não se encaixando em nenhuma das categorias de esporte.

Porém, concorda-se com González $(2004,2006)$ ao salientar que isso não se apresenta como um problema, pois a maioria dos esportes pode ser classificada, permitindo o agrupamento de modalidades de acordo com as características comuns identificadas na lógica interna.

Pelo fato de existir uma grande variedade no mundo do esporte - conforme Tubino (2001) são mais de quinhentas modalidades esportivas -, dificilmente se terá uma classificação que consiga abarcar todas. Entende-se que, mesmo deixando de contemplar um ou outro esporte, não se apresenta como algo que invalide ou desvalorize o sistema de classificação adotado na pesquisa.

Os professores também destacaram a possibilidade de oferecer uma melhor organização do conteúdo e de apresentar aos alunos um universo mais diversificado do esporte, como observado no relato:

Eu consigo trabalhar por categoria na minha aula, eu não preciso trabalhar modalidade específica, eu posso pegar a categoria de precisão e abordar a precisão com meus alunos de maneira lúdica, brincadeiras. Não preciso fazer o tiro com arco, posso fazer um arremesso ao alvo, eu tô trabalhando esse tema. Lutas, eu posso enquadrar lutas numa categoria maior. Eu acho que otimiza o trabalho pra quem de repente tem pouco tempo pra fazer, não precisa trabalhar tantas modalidades (PROFESSOR 8).

O comentário feito pelo professor 8 é determinante no sistema de classificação, pois havendo o tratamento do esporte em categorias e contando com a compreensão dos alunos, pode-se estabelecer uma lista de modalidades 
pertencentes à mesma categoria.

Na perspectiva da utilização desse modelo na prática pedagógica, também houve o seguinte posicionamento:

Quando a gente faz uma brincadeira de jogos de invasão, por exemplo, pebolim gigante, a gente usa três modalidades: basquete, handebol e futsal, consegue dentro do jogo fazer com que essas três atividades consigam ser jogadas ali, então eu acho que um jeito legal usar essas atividades, ter os jogos de invasão e já inserir essas três modalidades (PROFESSOR 7).

Os professores 1, 2 e 8 também ressaltaram que o sistema de classificação auxilia no tratamento de aspectos conceituais referentes ao esporte, possibilita uma conexão entre as modalidades pertencentes à mesma categoria de esporte e propicia uma continuidade do trabalho pedagógico ao longo do ano letivo no trato do conteúdo esporte, consolidando a compreensão do modelo.

Já os professores 5 e 6 apontaram para a possibilidade de organizar o trabalho em suas práticas pedagógicas futuras, sem estabelecer como referência as modalidades esportivas, mas estruturando unidades didáticas que contemplem cada categoria de esporte, inclusive refletindo na possibilidade de metodologias de ensino para cada categoria.

Essa observação vai ao encontro de um dos propósitos da Base Nacional Comum Curricular (BRASIL, 2018), que oferece o tratamento do elemento esporte na perspectiva das categorias, conforme é apresentado no sistema de classificação do esporte contemplado nesse estudo.

Quanto à relevância em se utilizar esse modelo de classificação do esporte para a formação dos alunos, destacaram-se os posicionamentos:

Eu acho que, com essa classificação, ficou mais fácil eles entenderem o objetivo do esporte, porque quando eu comecei a explicar a parte dos esportes com interação, quando eu coloquei campo, eles já foram: futebol, direto. Aí eu expliquei qual era o objetivo do futebol. A classificação tá muito ligada ao objetivo, então ficou mais claro pra eles entenderem o objetivo de cada esporte (PROFESSORA 6).

Eu acho que eles vão conseguir compreender que têm esportes que têm exigências de habilidades motoras diferentes, mas eles vão ter o mesmo objetivo, às vezes os esportes têm exigências motoras totalmente diferentes, mas tem o mesmo objetivo, qual é o objetivo no esporte de marca? Ver quem consegue atingir uma marca melhor, eu acho que isso é positivo pra eles estarem observando. (PROFESSORA 6).

Nos relatos da professora 6 , ressalta-se que os critérios utilizados para a classificação propiciaram um melhor entendimento dos objetivos das modalidades 
esportivas. Também se aponta para a necessidade de compreender que o fato de pertencer à mesma categoria não significa que as habilidades motoras específicas sejam semelhantes; isso pode ser exemplificado ao comparar os movimentos das provas de corridas do atletismo e as provas da natação, nas quais o propósito é estabelecer o menor tempo possível, porém os gestos técnicos são distintos.

A professora 1 destacou outra questão:

$\mathrm{Na}$ verdade, isso até facilita pra uma escolha deles do que eles gostariam de praticar, se é esporte com interação, sem interação. Se eles gostam mais de competir seria de marca, um objetivo de competir maior ou estético, mais pra quem gosta de beleza do esporte, pra eles seria ótimo, uma classificação legal, pra mostrar pra eles quais são os esportes que existem (PROFESSORA 1 ).

A professora 1 ressalta a importância dos alunos conhecerem uma ampla gama de modalidades esportivas, com a perspectiva de terem opções diversificadas para selecionarem e incorporarem a prática de um ou mais esportes no cotidiano.

A partir dos posicionamentos dos professores percebeu-se que responderam positivamente quanto à utilização do modelo de classificação, sendo possível verificar que a quantidade de apontamentos direcionados aos fatores positivos foi superior às possíveis dificuldades, inclusive estas, em certo momento, deram-se pela má interpretação de haver ou não interação entre adversários, do que propriamente se caracterizou como um problema ou algo inviável de ser desenvolvido.

Destaca-se também que os professores mencionaram outros aspectos favoráveis ao sistema de classificação, utilizando termos como: organização, estruturação, apresentação, diversidade, variedade, interesse e curiosidade, todos sinalizando positivamente e estando plenamente relacionados à proposta de utilização do modelo de classificação desenvolvido na pesquisa.

\section{CONSIDERAÇÕES FINAIS}

A participação no estudo estimulou os professores a realizar uma reflexão acerca de como tratam o conteúdo esporte durante o ano letivo, entendendo que o planejamento seguido em suas redes municipais de ensino e/ou unidades escolares não está oferecendo um tratamento pedagógico apropriado desse elemento da Cultura Corporal de Movimento.

Isso os levou a pensarem a respeito de uma reestruturação no planejamento do componente curricular para contemplar o conteúdo esporte, demonstrando que os professores participantes deste estudo apresentaram uma boa receptividade 
em relação às novas propostas de trabalho, transparecendo que estão preocupados em oferecer uma prática pedagógica de qualidade em seus ambientes escolares.

Cabe ressaltar que a maioria dos professores não tinha conhecimento prévio acerca dessa classificação do esporte, pois apenas o professor 2 havia participado de um curso sobre o assunto.

Os participantes demonstraram aprovação pelo sistema de classificação, levantando diversos fatores favoráveis para a sua utilização nas suas respectivas práticas pedagógicas, tanto em relação ao trabalho do professor: melhor apresentação, organização e estruturação do conteúdo, maior variedade e diversidade de modalidades esportivas contempladas, ruptura do tradicionalismo ao tratar do conteúdo esporte na escola; como também para a aprendizagem dos alunos: despertar do interesse e da curiosidade, aumento das possibilidades de aprendizagem e de proximidade das modalidades esportivas, identificação das características comuns e particularidades das modalidades pertencentes à mesma categoria de esporte.

Entretanto, é importante advertir que, a partir dos posicionamentos, dúvidas e até mesmo interpretações errôneas por parte de alguns participantes, pôde-se verificar que a leitura do artigo científico e do material didático referente ao caderno do professor e caderno do aluno não foi suficiente para que todos os professores obtivessem uma completa compreensão do modelo de classificação do esporte adotado na pesquisa, fato que foi superado com a exposição do professor sobre os critérios para classificação das modalidades e a realização das discussões durante os encontros.

Esse dado pode se apresentar como um problema, caso o professor somente receba o material referente ao sistema de classificação, sem haver uma explicação do mesmo, uma leitura complementar e a realização de exercícios propiciando um melhor entendimento e esclarecimento das dúvidas, como foi possível realizar nos dez encontros da pesquisa.

Outro aspecto a ser reforçado em relação ao sistema de classificação do esporte tratado no estudo é o fato de este modelo ser adotado na Base Nacional Comum Curricular (BRASIL, 2018), documento este que apresenta os objetivos de aprendizagem dos diferentes componentes curriculares nos anos iniciais e finais do Ensino Fundamental, norteando o trabalho pedagógico dos professores.

Sendo assim, entende-se que o modelo de classificação em questão receberá maior evidência, pois será utilizado como marco teórico para estruturação do conteúdo esporte na Educação Física escolar durante o período do Ensino Fundamental. Isso remete a uma valorização desse sistema de classificação do esporte, bem como a importância de verificar a compreensão e a avaliação dos 
professores durante o seu processo de implementação.

Nessa perspectiva também se adverte quanto à atenção que os cursos de formação inicial e continuada de professores de Educação Física em licenciatura devem ter, pois, com a utilização do sistema de classificação do esporte na Base Nacional Comum Curricular, mostra-se fundamental o tratamento desse modelo nas instituições de ensino superior que oferecem essas possibilidades de estudo.

\section{REFERÊNCIAS}

BARDIN, Laurence. Análise de conteúdo. Lisboa: LDA, 1991.

BARROSO, André Luís Ruggiero. Voleibol escolar: uma proposta de ensino nas três dimensões dos conteúdos. 2008. 226f. Dissertação (Mestrado em Ciências da Motricidade) - Instituto de Biociências, Universidade Estadual Paulista, Rio Claro, 2008.

BAYER, Claude. O ensino dos jogos desportivos colectivos. Paris: Vigot, 1994.

BENTO, Jorge Olímpio. Da pedagogia do desporto. In: TANI, Go; BENTO, Jorge Olímpio; PETERSEN, Ricardo Demétrio de Souza. Pedagogia do desporto. Rio de Janeiro:

Guanabara Koogan, 2006. p. 26-40.

BETTI, Mauro. Ensino de primeiro e segundo graus: Educação Física para quê? Revista Brasileira de Ciências do Esporte, Campinas, v. 16, n. 3, p. 282-287, 1992. Disponível em:

https://www.researchgate.net/profile/Mauro Betti/publication/280922054 Ensino de 10 e 20 graus educacao fisica para que/links/55cb4c6508aeca747d6bb448/Ensino-de10-e-2o-graus-educacao-fisica-para-que.pdf.

BETTI, Mauro. A Educação Física não é mais aquela. Motriz, Rio Claro, v. 1, n. 1, p. 8183, 1995. Disponível em:

http://www.rc.unesp.br/ib/efisica/motriz/01n1/10 Betti ponto form.pdf.

BRACHT, Valter. A constituição das teorias pedagógicas da Educação Física. Caderno Cedes, Campinas, n. 48, p. 69-89, 1999. Disponível em:

http://www.scielo.br/scielo.php?script=sci abstract\&pid=S0101-

$32621999000100005 \& \operatorname{lng}=$ en\&nrm $=$ iso\&tlng $=$ pt.

BRACHT, Valter. Esporte na escola e esporte de rendimento. Revista Movimento, Porto Alegre, v. 4, n. 12, p. 14-29, 2000/1. Disponível em:

https://seer.ufrgs.br/index.php/Movimento/article/view/2504/1148.

BRASIL. Base nacional comum curricular. Disponível em:

http://basenacionalcomum.mec.gov.br/wp-content/uploads/2018/02/bncc-20dez-

site.pdf. Acesso em: 20 de out. 2018.

BUNKER, David; THORPE, Rol. A model for the teaching of games in secondary schools. Bulletin of physical education, v. 18, n. 1, p. 5-8, 1982. Disponível em: https://brunel.rl.talis.com/items/2CB94388-2B83-DA7E-0184-EEB032DF663F.html.

DAMIANI, Magda Floriana et al. Discutindo pesquisas do tipo intervenção pedagógica. Cadernos de Educação, v. 45, p. 57-67, 2013. Disponível em: 
https://periodicos.ufpel.edu.br/ojs2/index.php/caduc/article/view/3822.

DAOLIO, Jocimar. Educação Física e o conceito de cultura. Campinas: Autores Associados, 2004.

DARIDO, Suraya Cristina; RANGEL, Irene Conceição Andrade (Coord.). Educação Física na escola. Rio de Janeiro: Guanabara Koogan, 2005.

DARIDO, Suraya Cristina (Org.). Educação Física escolar: compartilhando experiências. São Paulo: Phorte, 2011.

DUPRAT, Rodrigo Mallet; BORTOLETO, Marco Antonio Coelho. Educação Física escolar. Prática e didática das atividades circenses. Revista Brasileira de Ciências do Esporte, Campinas, v. 28, n. 2, p. 171-189, 2007. Disponível em:

http://revista.cbce.org.br/index.php/RBCE/article/view/63.

FORQUIN, Jean Claude. Escola e cultura: as bases sociais e epistemológicas do conhecimento escolar. Porto Alegre: Artes Médicas, 1993.

FRANCO, Laércio Claro Pereira. Atividades físicas de aventura na escola: uma proposta pedagógica nas três dimensões do conteúdo. 2008. 136f. Dissertação (Mestrado em Ciências da Motricidade) - Instituto de Biociências, Universidade Estadual Paulista, Rio Claro, 2008.

FREIRE, João Batista. Educação de corpo inteiro: teoria e prática da Educação Física. 3. ed. São Paulo: Scipione, 1992.

FREIRE, João Batista; SCAGLIA, Alcides José. Educação como prática corporal. São Paulo: Scipione, 2003.

GALATTI, Larissa Rafaela. Pedagogia do esporte: o livro didático como mediador no processo de ensino e aprendizagem dos jogos esportivos coletivos. 2006. 139f. Dissertação (Mestrado em Educação Física) - Faculdade de Educação Física, Universidade Estadual de Campinas, Campinas, 2006.

GARGANTA, Júlio. Para uma teoria dos jogos desportivos colectivos. In: GRAÇA, Amândio; OLIVEIRA, José. (Ed.). O ensino dos jogos desportivos. 3. ed. Lisboa: Universidade do Porto, 1998. p. 11-25.

GIL, Antonio Carlos. Como Elaborar Projetos de Pesquisa. 5. Ed. São Paulo: Atlas, 2010.

GRECO, Pablo Juan; BENDA, Rodolfo Novellino. Iniciação aos esportes coletivos: uma escola da bola para crianças e adolescentes. In: ROSE JÚNIOR, Dante de. Modalidades esportivas coletivas. Rio de Janeiro: Guanabara Koogan, 2006. p. 180-193.

GONZÁLEZ, Fernando Jaime. Sistema de classificação de esportes com base nos critérios: cooperação, interação com o adversário, ambiente, desempenho comparado e objetivos táticos da ação. Lecturas, Educación Física y Deportes, año 10, n. 71, 2004. Disponível em: https://www.efdeportes.com/efd71/esportes.htm.

GONZÁLEZ, Fernando Jaime. Projeto curricular e educação física: o esporte como conteúdo escolar. In: REZER, Ricardo (Org.). O fenômeno esportivo: ensaios críticoreflexivos. Chapecó: Argos, 2006. p. 69-109.

GONZÁLEZ, Fernando Jaime; BRACHT, Valter. Metodologia do ensino dos esportes coletivos. Vitória: UFES, Núcleo de Educação Aberta e a Distância, 2012. 
GONZÁLEZ, Fernando Jaime; DARIDO, Suraya Cristina; OLIVEIRA, Amauri Aparecido Bássoli (Org.). Práticas corporais e a organização do conhecimento. Esportes de marca e com rede divisória ou muro/parede de rebote: badminton, peteca, tênis de campo, tênis de mesa, voleibol, atletismo. Maringá: Eduem, 2017.

MESQUITA, Isabel; GRAÇA, Amândio. Modelos de ensino dos jogos desportivos. In: TANI, Go; BENTO, Jorge Olímpio; PETERSEN, Ricardo Demétrio de Souza. Pedagogia do desporto. Rio de Janeiro: Guanabara Koogan, 2006. p. 269-283.

OLIVEIRA, Amauri Aparecido Bássoli; DARIDO, Suraya Cristina; GONZÁLEZ, Fernando Jaime (Org.). Práticas corporais e a organização do conhecimento. Esportes de invasão: basquetebol, futebol, futsal, handebol, ultimate frisbee. Maringá: Eduem, 2014.

PAES, Roberto Rodrigues. Educação Física escolar: o esporte como conteúdo pedagógico do ensino fundamental. Canoas: Ulbra, 2001.

PARLEBAS, Pierre. Los universales de los juegos desportivos. Revista de Praxiologia Motriz, v.1, p. 15-30, 1996.

PARLEBAS, Pierre. Juegos, deportes y sociedades. Léxico de praxiología motriz. Barcelona: Editorial Paidotribo, 2001.

PARLEBAS, Pierre. Um novo paradigma em educação física: domínios da ação motora. In: GARCIA, Juan Pedro Fuentes Garcia; PÉREZ (coord.). Educação Física na Europa e qualidade didática em atividades físico-esportivas: livro minucioso. Conselho Provincial de Cáceres, 2003, p. 27-42.

RIO GRANDE DO SUL (Estado). Secretaria de Estado da Educação. Referencial curricular: lições do Rio Grande. Linguagens, códigos e suas tecnologias. Artes e Educação Física. v. 2. Porto Alegre, 2009.

RODRIGUES, Heitor Andrade. Basquetebol na escola: construção, avaliação e aplicabilidade de um livro didático. 2009. 92f. Dissertação (Mestrado em Ciências da Motricidade) - Instituto de Biociências, Universidade Estadual Paulista, Rio Claro, 2009.

SANTANA, Wilton Carlos. Pedagogia do esporte na infância e complexidade. In: PAES, Roberto Rodrigues; BALBINO, Hermes Ferreira. Pedagogia do esporte: contextos e perspectivas. Rio de Janeiro: Guanabara Koogan, 2005. p. 01-23.

SOARES, Carmem Lúcia et al. Metodologia do ensino da Educação Física. São Paulo: Cortez, 1992.

TUBINO, Manoel José Gomes. Dimensões sociais do esporte. 2. ed. São Paulo: Cortez, 2001.

TUBINO, Manoel José Gomes. Uma visão paradigmática das perspectivas do esporte para o início do século XXI. In: GEBARA, Ademir; MOREIRA, Wagner. Wey (Org.). Educação Física \& esportes: perspectivas para o século XXI. 9. ed. Campinas: Papirus, 2002. p. 125-139. 